\title{
The Analysis of the Influence of Information Environment on the Efficiency of Training Future Masters for Research Activity
}

\author{
Ihor Z. Bopko ${ }^{1}$, Bogdan S. Kryshchuk ${ }^{2}$, Liudmila I. Romanovska ${ }^{3}$, Yuriy L. Bryndikov ${ }^{3}$ \& Nataliya V. Synyuk ${ }^{3}$ \\ ${ }^{1}$ Department of English Philology and Methods of Teaching Foreign Languages, Humanities Faculty, Mukachevo \\ State University, Mukachevo, Ukraine \\ ${ }^{2}$ Department of Pedagogy, Faculty of Primary Education and Philology, Khmelnytskyi Humanitarian-Pedagogical \\ Academy, Khmelnytskyi, Ukraine \\ ${ }^{3}$ Social Work and Pedagogics Department, Humanities Faculty, Khmelnitskyi National University, Khmelnitskyi, \\ Ukraine \\ Correspondence: Ihor Z. Bopko, Department of English Philology and Methods of Teaching Foreign Languages, \\ Humanities Faculty, Mukachevo State University, 26, Uzhgorodska str., Mukachevo, 8960 Ukraine.
}

Received: June 10, 2020

Accepted: August 3, 2020

Online Published: August 4, 2020

doi:10.5430/ijhe.v9n7p24

URL: https://doi.org/10.5430/ijhe.v9n7p24

\begin{abstract}
The article presents the results of research on the problem of training future masters of humanities for research activity under the conditions of the information environment. The authors reviewed scientific literature, determined the mainstreams of the future masters' training for research activities, and the dynamics of their readiness for these activities, studied the influence of the information environment of higher educational institutions on the level of the development for research activities. They also developed the provisions for methodological recommendations. The information environment is understood as the possibility to obtain the necessary data, evidence, hypotheses, theories, etc. Much attention is paid to ensuring the quality of professional training through the introduction of stagewise higher education, the formation of the future masters' professional mobility under the labour market conditions. Based on the review of psychological and pedagogical literature, we determined the pedagogical conditions for the development of future masters' readiness for research activities: ensuring the future masters' training within the modern information environment; formation of the future masters' motivation for research activities in the information environment; introduction of a competent approach into the future masters of humanities training; ensuring the integration of academic subjects in the future masters' training for research activity. Based on the results of the study, we determined the main tasks of further research. The authors confirmed the reliability of the research results by the Student's t-test and Fisher's F-test.
\end{abstract}

Keywords: master's degree programme, future masters of humanities, information environment, higher educational establishment, pedagogical conditions, information and communication technologies

\section{Introduction}

A component of a stagewise education aimed at training masters for research activities and ensuring their mastery of research methods and means, ability to make well-balanced decisions, ability to solve them independently and analyse the results of research.

In fact, after graduation from higher educational establishment the master should be ready for professional activity in scientific institutions: scientific research institutes, laboratories, higher educational establishments. Among the positions in which masters can work, we allocate the position of the teacher of higher educational establishment, which he / she should combine with research activity.

In the context of educational informatization in higher educational establishments, future masters have new opportunities for cognitive activity, which allowed to increase the requirements for the master's intellectual, research level, his /her creative abilities (Shutenko et al., 2018). At the same time, it requires enough training in computer science and information technology, which is ensured by the creation of a modern information environment for the future masters' research activities (Higgins \& Cherrington, 2017; Hopper, Sanford, Hong \& Monk, 2016). 
At presents, professional competence of specialists of different specializations is supplemented by information competence (Weinberg, Hashimoto \& Fleisher, 2009). After all, the labour market, in fact, requires specialists who have professional mobility, the ability to adapt to modern working conditions quickly and critical thinking. At the same time, special attention is paid to the ability of a specialist to receive and process information, to use it in professional activity. And the acquisition of such skills is ensured by the constant work in the information environment (Hubert, Pickavance \& Hyberger, 2015; Shi, Awan \& Cristea, 2013).

The results of the theoretical and practical studies analysis of future masters of humanities preparation to work in the information environment, revealed several contradictions that interfere with this process:

- between the growth of the necessary information amount and the limited access to its obtaining;

— between the modern requirements for the future master's computer literacy and its level, as well as the availability of modern information environment in the higher educational establishment;

- between the needs of intellectually developed scientific personnel and their level to work in the information environment.

Therefore, the investigation was aimed at overcoming of these contradictions.

A number of national and foreign scientists aimed their research at: the problem of future masters preparation in the conditions of the higher educational establishments; considerable attention is paid to the scientific foundations of learning technology with the information and communication technologies implementation; the problem of the information environment influence on the efficiency of the educational process (Crockett, Latham \& Whitton, 2012).

Future masters' training is based on theoretical and methodological foundations (normative and elective courses, methodological approaches, didactic principles), practical training and Master thesis (research work). The main task of training is to create conditions for creative development of gifted personality and train specialists in the following activity areas: research (creative), scientific-pedagogical, managerial (industrial) (Fatahi, Moradi \& Zonoz, 2015).

Research is the common ground between the training areas of masters for all specialties.

The awareness of the relationship between education and science, the role of the educational environment in professional self-identity is one of the conditions for successful research activities of future masters. The key to successful professional activity is the well-formed professional identity (Glaze, 2018), as it provides self-identification in the educational environment and future activity (Bachari, Abdelwahed \& Adnani, 2010).

The process is considered in the higher educational establishment information environment, as the environment provides the independence of learning, the choice of methods and forms of training, the individuality of judgments, the independence of decision-making and their implementation.

Nowadays, there is a process of informatization of all branches of science and education, which requires a new level of the future specialists' research activities organization (Murray, 2011). But the question concerning the information environment influence on the quality of future masters of humanities training has been insufficiently studied (Hofkirchner \& Burgin, 2017). This finds its manifestation in the absence of practically tested pedagogical conditions and model for the future masters' research activity organization.

Aims and tasks are to investigate and substantiate the problem of effective training of future masters of humanities for research activity in the information environment in higher educational establishments.

\subsection{Objectives of the Study}

1. To analyse the state of the future masters of humanities training for research activity in the information environment.

2. To identify contradictions of future masters' training for professional activity.

3. To mark the possible ways of the future masters of humanities training for professional activity.

4. To define and implement the most effective methods of pedagogical experiment and calculations for the accuracy of the study results.

\section{Research Methods}

To solve the objectives a complex of the following research methods has been used:

- theoretical (analysis of psychological and pedagogical literature on the problem of informatization of education in higher educational establishments, synthesis, systematization, comparison, modelling and generalization - for 
processing of scientific sources, definition of the essence and peculiarities of pedagogical teaching technology, development of its model);

- empirical (observations, questionnaires, surveys, pedagogical experiment, study of the results of research activities, which ensured the study of the state of the problem practically and the influence of pedagogical technology for the development of readiness of future masters for research activity);

- methods of processing the results at different stages of the study (quantitative processing of the results of the pedagogical experiment using the Student's t-test and Fisher's F-test (Kyverjalg, 1980).

\section{Research Results}

Informatization - a set of interconnected organizational, legal, political, socio-economic, scientific and technical, production processes aiming to create the conditions for meeting the information needs of citizens and society through the development (Thomas, 2011), information systems development and implementation (Hofkirchner \& Burgin, 2017), networks, resources and technologies based on the application of modern computer and communication technology (Karimi \& Kangavari, 2012; Yasir \& Sami, 2011).

The future masters' training for research activity is increasingly important in the continuous training of specialists in higher educational establishments. That is due to the increased requirements for the training of appropriate level professionals. Among the factors influencing the quality of professionals' training are the informatization of education, the information and communication technologies introduction, means of modern technologies implementation.

There are various classifications of the information environment in the psychological and pedagogical literature: information and educational, information and teaching, information environment of educational establishment (Rani, Nayak \& Vyas, 2015; Latham, Crockett \& McLean, 2014). The authors scrutinise the role of the information environment in higher educational establishments (Akbulut \& Cardak, 2012). Under the information environment, the authors understand the pedagogically and technically organized informational interaction of the participants of educational process. Suggestions have been offered to solve the problem of the masters' degree students work organisation in the information environment by integrating information on traditional and electronic media, computer and telecommunication technologies. Much attention is paid to the information environment during the process of education informatization. Yang, Hwang and Yang, (2013) put this concept into circulation and considered the information environment as "the possibility of obtaining the necessary data, evidence, hypotheses, theories, etc" (Fig. 1.).

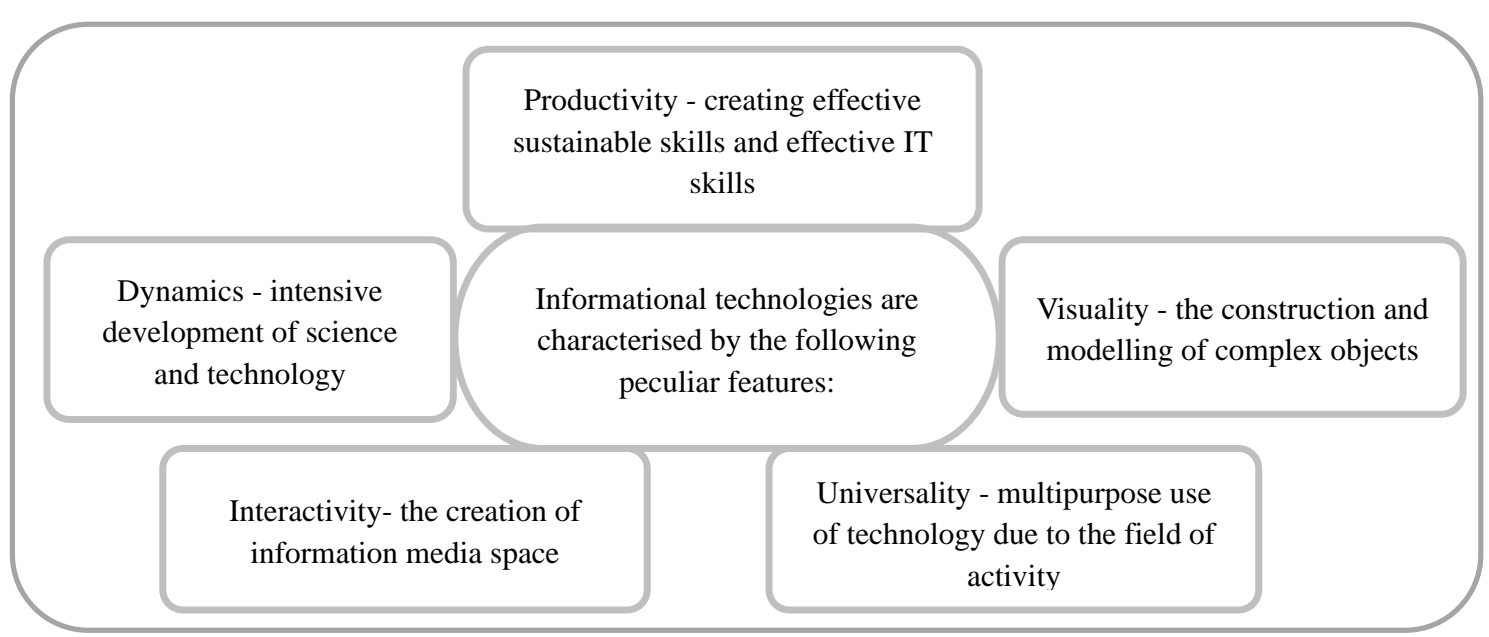

Figure 1. Characteristic features of information technologies in the training of future masters of humanities

The future masters' skills acquisition in the information environment provides free management of information technologies and means of their use. In this case, different types of information technologies are used. The greater the number of these technologies, the more effective is the educational process.

The analysis of literary sources showed that the future masters' training should be aimed at the formation of various professional qualities, among which we distinguish:

- managerial (provides a complete information exchange, automation of administrative and pedagogical processes);

- communication (combines logistical, information and human resources); 
- organizational (forms the availability and relevance of informatization to the needs of each future professional (Sanders \& Bergasa-Suso, 2010; Scott, Rodríguez, Soria \& Campo, 2014).

The information environment creation is in direct dependency on various factors, among which we distinguish:

1. Informatization. It is based on the role of information in the social and educational development of the future professional, contributes to the process of solving important pedagogical problems with the use of information knowledge.

2. Information resources. Information becomes a real substance on which the results of many educational and upbringing processes depends on.

3. Information Technologies. Information technologies are the integral part of the educational process, the level of their implementation depends on the information culture, and, respectively, the quality of obtaining, storage and processing of the information.

The study of the information environment influence on the future masters training involved elimination of contradictions that has been identified in the process of investigation, because the factor of the information environment is one of the significative factors in shaping the information culture of the future master of humanities.

The quality of professional training of a professionally competent master who is able to develop modern curricula, have effective methods of teaching and diagnostics process organization, depends on the level of readiness of the future master of humanities for research activity in the information environment.

Training of the professionals of all categories is the basis of continuous education, taking into account the Ukraine's entry into market relations and increasing the professional mobility of future masters. The educational programs of training, taking into account the new concept of masters training, are divided into: research (deepening of researches in one of scientific fields - 2 years of study), professional (development of professional and formation of managerial competences - 1.5 years of study), career (improvement of theoretical and practical knowledge for career development and training for management activities - 1-1,5 years of study).

According to educational programs, the master should be ready for professional activity in research institutes, laboratories at the positions of scientific researchers, teachers of higher educational establishments. Possible ways of the formation of future masters' readiness for research activity in the conditions of information environment, require further elaboration.

Analysis of the psychological and pedagogical literature has determined the direction of future masters' training for the formation of the qualities that masters should possess: analyticity and consistency of thought, critical thinking, interpersonal skills, emotional - volitional stability, professional competence, decision-making autonomy, and single-mindedness, responsibility, information competence, desire to continuous learning, motivation for success, adequate self-evaluation, professional culture, self-actualization. The master's curriculum is consistent with the bachelor's training plans, which helps to consolidate the skills of scientific, pedagogical and research activities. However, the issue of future masters training for research activity needs further consideration.

\section{Discussion}

Masters' training is divided into theoretical and practical. Based on current requirements for professionals, future masters of humanities should possess theoretical knowledge of the fundamentals of the humanities and specialized disciplines, know the state language, have the ability to conduct a dialogue, know a foreign language for free communication with foreign experts, read and translate journal and newspaper articles and other texts in the fields of science, technology and society. A master should possess a creative thinking, clarity of verbal expression, be motivated.

Scientists have developed modern methods of the professionals' personal and professional qualities assessment, which are the combination of traditional and innovative methods.

Among the most commonly used and those suitable for evaluation of specialists of different specializations, that is, the universal ones, we used identification of the levels of different competencies of students.

The methods of the parametric method of evaluating the effectiveness of pedagogical technology have been used to diagnose the results of the study. The comparison of the results before and after the experiment has been conducted to diagnose readiness of the future masters of humanities for research activity in the information environment.

It has been investigated that the pedagogical technology of training for research activity of the future master of humanities developed by the author performs the following functions: provision of positive motivation for research 
activity, the development of the need for self-improvement and personal experience of research activity; as well as it provides study of the management mechanisms of the research activity process of the future masters of humanities, aimed at the future specialist's personal development of the and the acquisition of research activity skills; contributes to the individual peculiarities formation of the research practice in the information environment.

Scientists note the significant influence of the information environment on the formation of practical skills in the process of conducting research activities in the future master of humanities training. This influence is manifested in personal and professional self-improvement, since it requires independent work in the information environment (Nance, Hay, Dodge, Seazzu \& Burd, 2009). It also helps to acquire computer skills, modern programs for information collection and processing.

Whereas the future masters training is performed in order to form three groups of masters' qualities (managerial, communication and organizational), the process was realized through the development of readiness for acquiring professional knowledge by means of self-education, for personal career development; abilities to develop and execute the program for professional growth and development of creative abilities independently. In the programs considerable attention is paid to the development of the business, communicative, reflexive qualities (they form the basis of the three groups of qualities mentioned above) needed by the future scientist.

At the same time, the distribution of skills has been suggested, according to the formation of practical and motor, perceptual, language, mental and intuitive skills, the process of creative thinking development methods mastery; the process of spoken and written business speech mastery.

The authors studied the basic requirements for training of the masters of humanities: knowledge of basic methodological approaches, didactic principles, pedagogical theories and concepts in the humanities and socio-economic sciences, ability to analyse and apply the methods of these sciences in different types of professional and social activities; readiness for continuing education and professional activity in a foreign-language environment; acquiring skills of the organization of research work with the use of computer equipment in their professional activity; ability to acquire knowledge independently.

Studying the problem of students' organisation of research activities, we identified several forms of such activities: work of scientific circles, problem and project groups, scientific laboratories, student scientific and creative societies, implementation of state-financed and self-supporting scientific topics, collaborative studies by the employees of department and faculties, which ensures the efficiency of the information environment in higher educational institutions, design and project centres, competitions, skills contests and preparation of publications on the research results.

It has been determined that the educational and professional program of master's training contains educational and research components. The educational component is aimed at forming a more holistic, advanced vision of professional activity, the extent and fundamentality of education, its maximum approximation to the current level of scientific knowledge in the relevant field. The research component of the program is related to the scientific terms of reference of the department. The main functions of research activities are: analytical; orientation; prognostic; informational; innovative; modelling; system forming; reflexive; optimizing.

Master's thesis hold a special place in the research activity of master's degree students. The aim of the master's thesis is to apply and produce new knowledge in order to solve problematic pedagogical and research tasks in the field of education (including primary).

Master's thesis is the final stage in future masters' training. It is confirmation of master's qualification - a form of reporting of the training quality of master's degree students. The thesis contains the solution of a specific scantily explored scientific problem, important and relevant for the given field of knowledge, and scientifically substantiated and interrelated technological (scientific and methodological) developments.

The final stage of training is master's thesis defence, preceded by:

- reports at scientific and methodological conferences and seminars;

- preparation and defence of abstracts, reports on the research works implementation;

- preparation and publication of the results of scientific work in periodicals.

Supervision of master's work on scientific issue is controlled through a system of midterm attestation

Master's thesis is performed independently, but under the supervision of a scientific supervisor. It characterizes the identity of the future master, the degree of his / her independence and his / her training quality. 
In order to complete the master's thesis, future master should go through the following stages: preliminary, conceptually methodological, organizational and practical, generalizing, dissemination of innovative pedagogical experience. The main tasks of the previous stage are: to carry out the analysis of the issue, the degree of its coverage in the psychological and pedagogical literature; the determination the aim, subject, object and the objectives of the study; to identify existing contradictions and outline the ways to resolve them; the working hypotheses; outline of the study plan. At the conceptual and methodological stage, the analysis of curricula is carried out, which, if necessary, changes, search and selection of the diagnostic apparatus, necessary methodology, methods of statistical processing of results are made. At the organizational and practical stage, evaluation of the research and experimental part of the research work is carried out. The generalising stage involves the obtained results analysis, the substantiation of the research efficiency, confirmation of the correct hypothesis, registration of the results of the research work in the form of a scientific report. The stage of innovative pedagogical experience dissemination involves preparation and printing of the main scientific results of the research.

Another direction of the development of readiness of the future masters for research activity is the use of information and communication technologies. For this purpose, considerable attention is paid to the creation of information environment in higher educational establishments.

The acquisition with foreign experience of the information environment organisation (via Internet resources), allows to find out the state of information and communication technologies implementation in the master's training (Encalada \& Sequera, 2017).

Online Master's Degree training programs in Engineering at Arizona State University is the most popular, commercial site http://www.masterguide.org - it is the source of information on higher education in Europe. This site hosts major master's programs in the UK, France, Germany, Belgium, Italy, Finland, Denmark, Sweden and other European countries (Alma Channel, 2008). Substantial assistance in training the national masters is provided by the Italian side (Alma Channel, 2008) from the course "Master in Problems of Cooperation in International Education".

Very useful for master's degree students are the sections about grants, the MBA (Master of Business Administration) and advice for young scientists concerning the participation of international conferences / seminars and writing of grant applications.

Significant assistance in organisation of computer information environment is provided by a variety of services, applications, portals (service package "Google Apps for Education", scientific video content and YouTube Internet channels) (Al-Araibi, Mahrin \& Yusoff, 2019; Romero, Espejo, Zafra, Romero \& Ventura, 2013).

Google APPS - an environment which provides the following means: Gmail; Google Calendar; Google docs; Google Groups; Google Talk; Google Sites, iGoogle (Bazzaza \& Salah, 2015; Despotović-Zrakić, Simić, Labus, Milić \& Jovanić, 2013).

The investigation of the future masters' readiness for research activity has shown that future masters of humanities (73.4\%) understand the existence of a close link between research activity and their attitude to future professional activity. Only $46.2 \%$ of the respondents had an idea about the methods of processing scientific literature, and $32.3 \%$ about the writing rules of scientific articles, reports, abstracts.

The survey revealed the problems of future masters of humanities, connected to the ability to organize their own research activity, to work in the information environment. We relate this to the identified contradictions. Among the respondents, only $21.5 \%$ of future masters to a full extent have information about the requirements to their training.

The following components of the future masters of humanities' readiness for research activity have been distinguished: motivational component - ensures the training orientation into the right direction, stimulates the appearance of motives for research activity, determines the positive attitude to such activity due to their profession, influences the formation of the other components. The level of the component is determined by the criteria: the level of the motives for research activity, developing the ability to conduct research using the information environment; the information component ensures the exchange of information. The main criteria for this component are: the degree of information culture development; the possession of working means in the information environment, the ability to use interdisciplinary communication; the level of communicative skills in the information environment. The behavioural (praxeological) component involves the possession of modern scientific methods of research by future masters of humanities. To the main criteria of this component belong: the possession of professional knowledge; organizational skills; selection and application of optimal methods, techniques and organizational forms in the research activity organization; possession of research abilities and the research skills level; the ability for self-study, self-education, self-development and self-criticism. 
According to the results of the research, the levels of readiness for research activity have been determined: high, sufficient, medium and low. Studies have shown, that for these levels, the significant difference between them can be marked as well as results can be clearly recorded.

Characteristic features for the master's degree students, referred to high level are the awareness of the importance of research activity, organizational flexibility, the desire to study and apply innovation, the manifestation of creative abilities in research activity, possession of logical and creative thinking. We refer the master's degree students who have a strong interest in research activities, have sufficient working skills in the information environment, are able to conduct the experiment and make adjustments in its procedure, are able to analyse the results to the sufficient level.

Those who possess methods of information perception and processing, distribution of information flows, information and communication training technologies and independent activity, able to acquire products of the curriculum are referred to middle level. The low level of readiness for research activity is characterized by the presence, to a greater extent, of theoretical knowledge of scientific experiment organization, insufficient development of research skills and communication skills, the ability to identify patterns, rules of professional activity, insufficient acquaintance with innovations.

It has been found that, the correct selection of pedagogical conditions is among the factors having a significant effect on the efficiency of research activity skills formation. Therefore, the pedagogical conditions for the training efficiency of the future masters of humanities have been determined.

The following pedagogical conditions for the development of readiness of future masters of humanities for research activities have been chosen: ensuring the future masters training with a modern information environment; formation of future masters of motivation for research activity in the information environment; implementation of a competent approach in the training of future masters of humanities; ensuring the academic disciplines integration in the future masters' training for research activity.

The first condition is to ensure the future masters' training with a modern information environment. Its importance is connected with the introduction of modern training methods of specialists in higher educational establishments based on information and communication technologies. To implement these technologies without an established information environment makes no sense.

Structured electronic databases have been established; processes of traditional and distance learning have been provided; the communications networks within the educational establishment and between the establishments have been created.

The master's degree students have an access to these databases, as well as their scientific supervisors, who also have the opportunity to use social networks, blogs, chats in the information environment, provide the necessary material for the investigation, recommend interesting Internet links, to update databases on completed scientific developments, to conduct online consultations, to create online scientific conferences between future masters of higher educational establishments.

The next pedagogical condition was the formation of the future masters' motivation for research activity in the information environment. Motivation is an important and complex process. There are several stages in its formation: preparatory, main, incentive.

At the first stage, basic ideas about the fundamentals of research activity were formed, the acquaintance with scientific supervisors took place, the rules of research organization and a theoretical framework for the study were outlined, as well as tasks were assigned.

The second stage - aimed at the creation of a positive attitude toward research activity. At this stage, the influence of external and internal conditions have been provided for the involvement of motives for participation in research activity. These conditions include positive influence of external and internal factors, with the aim of transition of external factors into internal factors, which ensured their interaction. The main attention was paid to the formation of motives for research activities, the manifestation of interest in scientific knowledge. At this stage, the master's degree students are acquainted with the methods of organisation of research activity.

In the third stage, the individualization of training is carried out. Each master's degree student works on this / her own program. The program provided a specific topic, the content of the work, a list of literature sources on the problem under consideration, the directions for future research and choice of methods for conducting the experiment. The research results, methods of mathematical statistics and analysis of the results are subdivided as separate parts.

The next pedagogical condition was the implementation of a competent approach in the training of future masters of 
humanities. Nowadays, more and more scientific researches are devoted to the implementation of pedagogical approaches in the specialists' training and their role in educational process. The competence approach takes a significant place in this process, based on the concepts of "competency", "competence" and "professional competency". The concept of "professional competency" includes the experience of practical activity.

Therefore, the future masters' training was aimed at practical orientation, considering it as a specialist's ability to handle different professional situations properly. For this purpose, a collection of exercises has been prepared, with examples of different professional situations, that relate to problem of investigation and some examples of their solutions, as a model.

The fourth pedagogical condition - to ensure the integration of academic disciplines in the future masters training for research activity.

The implementation of this condition based on the integration of disciplines: "Pedagogy", "Fundamentals of scientific research"; "Higher Education and the Bologna Process", "Philosophy of Science", "Pedagogy Higher Education", "Methodology of Pedagogical Research", "Management and Marketing of Modern Education", "Preventive Pedagogy"; "Foreign Language for Specific Purposes", "Actual Problems of Primary Education Pedagogy ".

The following practices have been used to strengthen the practical component: educational, pedagogical; master thesis writing. Studies have shown that the implementation of academic disciplines integration in higher educational establishments in the research activities for the future masters of humanities requires harmonisation and further research.

For the successful realization of the selected pedagogical conditions, there was a need to develop a special course that would contribute to the acquisition of practical skills: information, practical, analytical and synthetic, communicative, prognostic, diagnostic.

For this purpose, a special course "Methodical Aspects of Master's Thesis Preparation" was prepared, which is the result of the integration of programs of the above disciplines, combining the formation of practical and theoretical skills for the research activity performance.

It has been proved that the chosen pedagogical conditions contribute to the achievement of the goal and increase the level of research activity, to the development of scientific potential of future masters of humanities.

To check the research results, formulation of conclusions on the obtained indicators of readiness of future masters for research activities in the information environment, the empirical results have been compared. The reliability of the results was proved by statistical methods.

For this purpose, the data of the null hypothesis have been tested, the essence of which is that the difference in the indicators of the levels of formation of each component of the future masters' readiness for research activity in the information environment at the stage of initial and final control in CG groups is not dependent on the learning technology, but is the result of the natural course of the educational process.

The obtained results were compared with the results of the dynamics of same levels of readiness of future masters of humanities at the beginning and the end of the experiment.

The essence of the alternative hypothesis is that the difference in the results indicators of the initial and final future masters' readiness for research activity in the information environment, who studied in the experimental groups, is due not to random factors, but due to targeted training conditions.

For the statistical analysis of the data, we used the method of comparing the variances using the Fisher F-test (Kyverjalg, 1980), determined by the following formula:

$$
F_{e m p}=\frac{\sigma_{1}^{2}}{\sigma_{2}^{2}}
$$

where $\sigma_{1}^{2}-$ is greater of the variances in the initial or final determination of the future masters' readiness for research activity in the information environment; $\sigma_{2}{ }^{2}$ - lesser of the variances in the initial or final determination of the future masters' readiness for research activity in the information environment;

The variance is determined by the formula: 


$$
\sigma^{2}=\frac{\sum f\left(x_{i}-\bar{x}\right)^{2}}{N}
$$

where $\mathrm{f}-$ is the number of grade points $5,4,3$ or $2 ; x_{i}-\bar{x}$ - the difference between the individual values of the grade points $(5,4,3,2)$ and the grade point average; $\mathrm{N}$ - is the number of future masters of humanities in the group where the variance was calculated.

The pilot testing has been carried out on the basis of Mukachevo State University, Khmelnytskyi National University and Khmelnytskyi Humanitarian-Pedagogical Academy.

In total, 124 future Masters were involved in the testing, from which experimental (EG) and control (CG) groups have been formed. They major in the following field of study: "Primary Education", "Musical Arts", "Social Work".

The number of the master's degree students of EG and CG was 61 and 63 respectively.

The parametric method of the efficiency estimation of pedagogical technology of future masters' readiness for research activity in the information environment has been used in the research. It provided the comparison of two key parameters: quality of specialists' training with pedagogical conditions implementation and traditional technology.

It has been established that the investigated pedagogical conditions ensure the efficiency of preparation for research activity.

For the statistical analysis of the data, we used the method of comparing the variances using the Fisher F-test.

The results of the study are represented in the following table. The analysis of the indicators presented in the table shows the positive dynamics of change in the preparation for research activity of future masters of humanities in the information environment (Table 1).

Table 1. The effectiveness of the development of readiness for research activity of future masters of humanities in the information environment

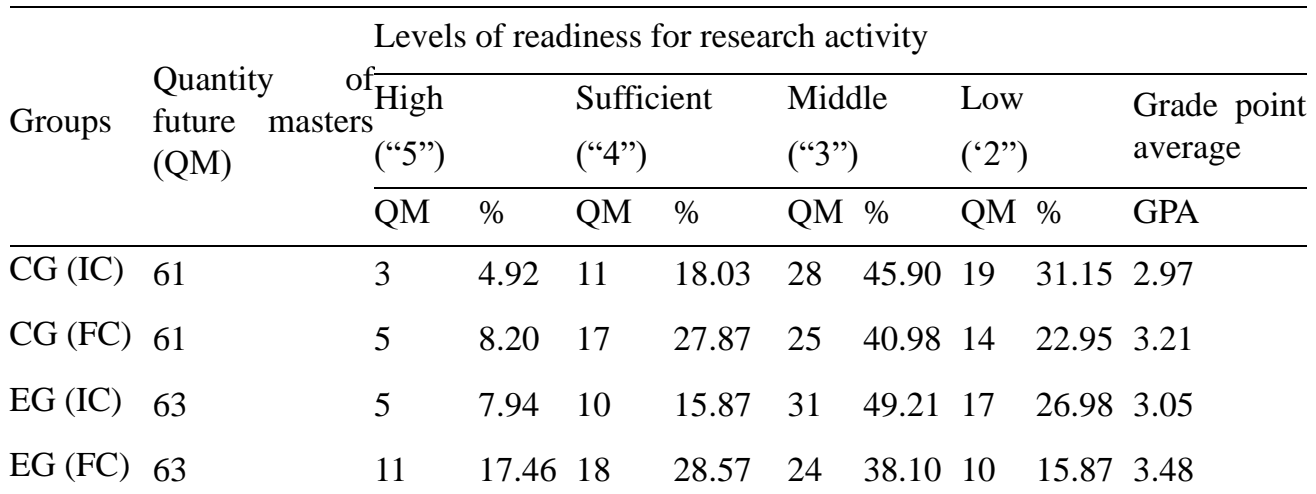

At the initial stage of the study, the indicators in EG and CG are almost the same (within the margin of error). The closest results have been recorded at high and sufficient levels (at the high level the difference is $3.02 \%$, and at the sufficient $-2.16 \%$ ).

During the experiment, significant changes occurred in the EG. Thus, at the high level the number of master's degree students increased by $9.52 \%$, at the sufficient level - by $12.70 \%$, at the middle and low level their number decreased by $11.11 \%$ and $11.11 \%$, respectively.

The analysis of the results in the CG showed that the changes were less intense.

At the high level the number of master's degree students increased by $3.28 \%$, at the sufficient level - by $9.84 \%$. At the middle and low level the number of master's degree students decreased by $4.92 \%$ and $8.20 \%$ respectively. The results obtained are shown in the diagrams (due to the number of students who participated in the experiment) (Figure 2).

The result of the introduction of pedagogical conditions was the quantitative and qualitative changes of the indicators of the future masters' readiness for their research activity in the information environment.

Studying the results of the experiment, it has been determined that the positive changes of the future masters' training 
are explained by: the introduction of modern training methods based on the information environment; introduction of information and communication technologies; introduction of pedagogical conditions that take into account the work in the information environment; participation in scientific-practical conferences, competitions of scientific works, skills contests, scientific publications.

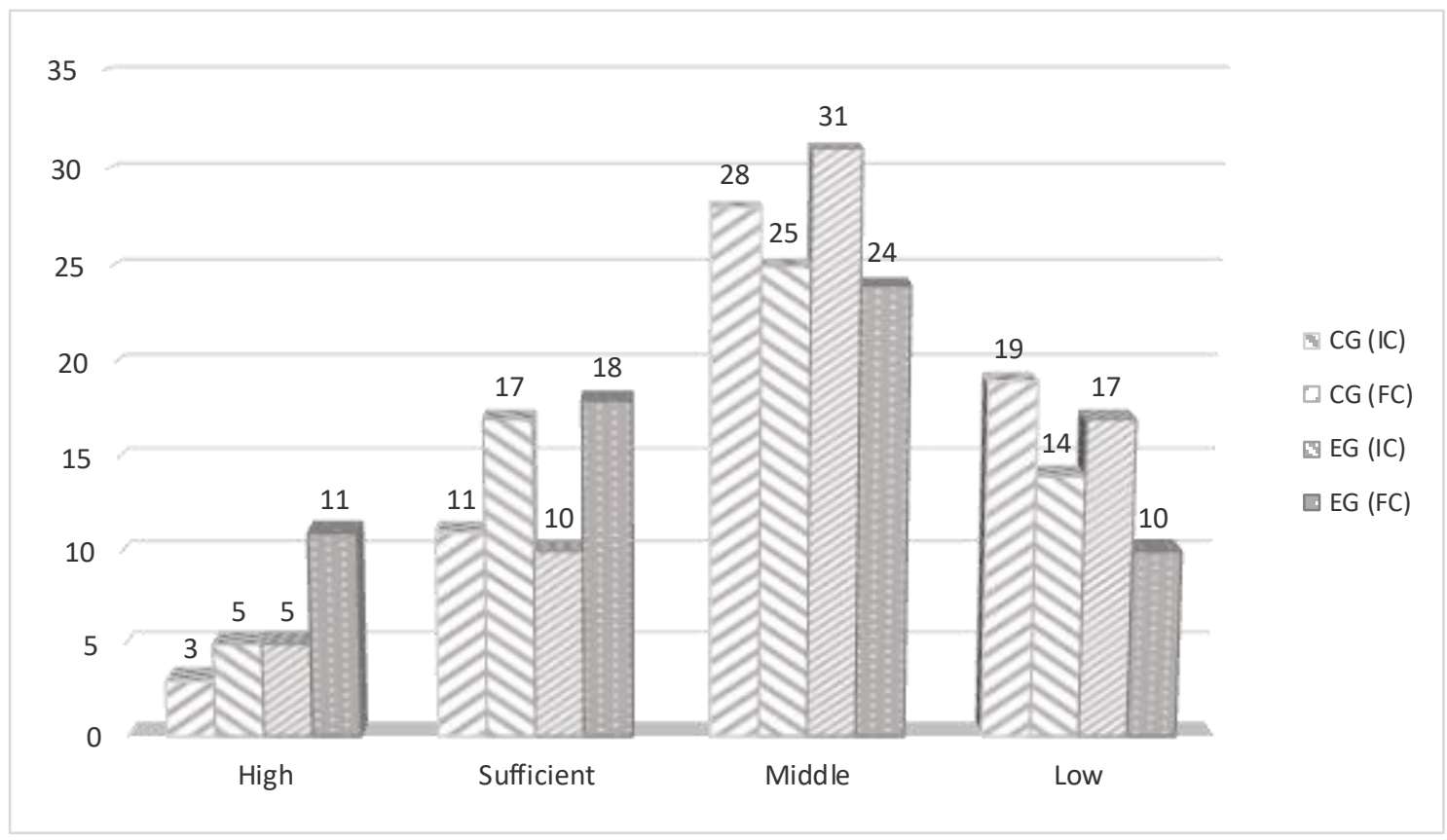

Figure 2. Dynamics of the levels of readiness for research activity of future masters of humanities in the information environment

\section{Conclusion}

1. Analysis of the psychological and pedagogical literature showed that the problem of training future masters of humanities has not been sufficiently studied. The issues on the training quality improvement of these specialists for research activity under certain pedagogical conditions that will be effective in the information environment were outside the purview of scientists.

2. In the course of the research the efficiency of pedagogical conditions for the development of readiness of the future masters for research activity in the information environment has been proved (provision of the future masters' training with modern information environment; the formation of future masters' motivation for research activity in information environments; the competence approach implementation in the training of the masters of humanities; ensuring the integration of academic disciplines in the future masters' training for research activities).

3. The efficiency of future masters' readiness for research activity was determined by its components, criteria and indicators of the levels of its formation. The following components have been chosen: the motivational component has been determined by the criteria - the level of the motives for research activity, developing the ability to conduct research using the information environment; the information component - has been determined by the criteria - the degree of information culture development, the possession of working means in the information environment, the ability to use interdisciplinary communication, the level of communicative skills in the information environment; the behavioural (praxeological) component - has been determined by the criteria - the possession of professional knowledge, organizational skills, selection and application of optimal methods, techniques and organizational forms in the research activity organization; possession of research abilities and the research skills level; the ability for self-study, self-education, self-development and self-criticism

4. The comparative analysis of the research results showed the efficiency of the development of readiness of the future masters in the information environment under certain pedagogical conditions. During the experiment, significant changes occurred in the EG. Thus, at the high level the number of master's degree students increased by $9.52 \%$, at the sufficient level - by $12.70 \%$, at the middle and low level their number decreased by $11.11 \%$ and $11.11 \%$, respectively. 
The reliability of the research results confirmed by the Fisher's F-test.

The promising areas for further research on the issue concerning the future masters' training for research activity we see in the development of structural and logic model of the formation of skills for conducting the research activity in the information environment.

\section{Reference}

Akbulut, Y., \& Cardak, C. S. (2012). Adaptive educational hypermedia accommodating learning styles: A content analysis of publications from 2000 to 2011. Computers in Education, 58(2), 835-842. https://doi.org/10.1016/j.compedu.2011.10.008

Al-Araibi, A. M., Mahrin, M. N., \& Yusoff, R. C. M. (2019). Technological aspect factors of E-learning readiness in higher education institutions: Delphi technique. Education and Information Technologies, 24(1), 567-590. https://doi.org/10.1007/s10639-018-9780-9

Alma Channel. (2008). La plattforma di e-learning dell'ateneo [The university's e-learning platform]. Retrieved from https://servera.almachannel.unibo.it/democooperazione/handlers/almachannel/components/LoginPage.viewDefa ult

Bachari, E. E., Abdelwahed, E. H., \& Adnani, M. E. (2010). Design of and adaptive e-learning model based on learner's personality. Ubiquitous Computing and Communication Journal, 5(3), 1-8.

Bazzaza, M. W., \& Salah, K. (2015). Using the Cloud to Teach Computer Networks. In I. Raicu, O. Rana, \& R. Buyya (Eds.), 2015 IEEE/ACM 8th International Conference on Utility and Cloud Computing (UCC 2015), 310-314. Los Alamitos, CA: IEEE Computer Society. https://doi.org/10.1109/UCC.2015.49

Crockett, K., Latham, A., \& Whitton, N. (2012). On predicting learning styles in conversational intelligent tutoring systems using fuzzy decision trees. International Journal of Human-Computer Studies, 97, 98-115. https://doi.org/10.1016/j.ijhcs.2016.08.005

Despotović-Zrakić, M., Simić, K., Labus, A., Milić, A., \& Jovanić, B. (2013). Scaffolding environment for e-learning through cloud computing. Journal of Educational Technology \& Society, 16(3), 301-314.

Encalada, W. L., \& Sequera, J. L. (2017). Model to Implement Virtual Computing Labs via Cloud Computing Services. Symmetry, 9(7), 117. https://doi.org/10.3390/sym9070117

Fatahi, S., Moradi, H., \& Zonoz, A. N. (2015). A computational model to determine desirability of events based on personality for performance motivational orientation learners. In P. Zaphiris, \& A. Ioannou (Eds.), Learning and collaboration technologies, 227-237. Cham, Switzerland: Springer International Publishing. https://doi.org/10.1007/978-3-319-20609-7_22

Glaze, A. (2018). Teaching and learning science in the 21st century: Challenging critical assumptions in post-secondary science. Education Sciences, 8(1), 12. https://doi.org/10.3390/educsci8010012

Higgins, A., \& Cherrington, S. (2017). What's the story? Exploring parent-teacher communication through e-portfolios. Australasian Journal of Early Childhood, 42(4), 13-21. https://doi.org/10.23965/AJEC.42.4.02

Hofkirchner, W., \& Burgin, M. (Eds.) (2017). The Future Information Society: Social and Technological Problems. Singapore, Singapore: World Scientific Publishing Company. https://doi.org/10.1142/10015

Hopper, T., Sanford, K., Hong, F., \& Monk, D. (2016). Electronic portfolio development in three professional programs: Conceptual framework and summary of initial findings. Journal of Technologies \& Human Usability, 12(2), 13-35. https://doi.org/10.18848/2381-9227/CGP/v12i02/13-35

Hubert, D., Pickavance, J., \& Hyberger, A. (2015). Reflective e-portfolios: One HIP to rule them all? Peer Review, 17(4), 15-18.

Karimi, S., \& Kangavari, M. R. (2012). A computational model of personality. Procedia - Social and Behavioral Sciences, 32, 184-196. https://doi.org/10.1016/j.sbspro.2012.01.029

Kyverjalg, A. A. (1980) Research Methods in Professional Pedagogics. Tallinn, Estonia: Valgus.

Latham, A., Crockett, K., \& McLean, D. (2014). An adaptation algorithm for an intelligent natural language tutoring system. Computers \& Education, 71, 97-110. https://doi.org/10.1016/j.compedu.2013.09.014 
Murray, P. (2011). The Sustainable Self: A Personal Approach to Sustainability Education. Washington, DC: Earthscan. https://doi.org/10.4324/9781849775212

Nance, K., Hay, B., Dodge, R., Seazzu, A., \& Burd, S. (2009). Virtual laboratory environments: Methodologies for educating cybersecurity researchers. Methodological Innovations Online, 4(3), 3-14. https://doi.org/10.4256/mio.2010.0002

Rani, M., Nayak, R., \& Vyas, O. P. (2015). An ontology-based adaptive personalized e-learning system, assisted by software agents on cloud storage. Knowledge-Based Systems, 90, 33-48. https://doi.org/10.1016/j.knosys.2015.10.002

Romero, C., Espejo, P. G., Zafra, A., Romero, J. R., \& Ventura, S. (2013). Web usage mining for predicting final marks of students that use Moodle courses. Computer Applications in Engineering Education, 21(1), 135-146. https://doi.org/10.1002/cae.20456

Sanders, D. A., \& Bergasa-Suso, J. (2010). Inferring learning style from the way students interact with a computer user interface and the WWW. IEEE Transactions on Education, 53(4), 613-620. https://doi.org/10.1109/TE.2009.2038611

Scott, E., Rodríguez, G., Soria, Á., \& Campo, M. (2014). Are learning styles useful indicators to discover how students use scrum for the first time? Computers in Human Behavior, 36, 56-64. https://doi.org/10.1016/j.chb.2014.03.027

Shi, L., Awan, M., \& Cristea, A. I. (2013). Evaluation of social personalized adaptive e-learning environments: End-user point of view. In A. V. Jones, \& N. Ng (Eds.), Proceedings of 2013 the 3rd Imperial College Computing Student Workshop (ICCSW'13), 103-110. Dagstuhl, Germany: Schloss Dagstuhl - Leibniz-Zentrum fuer Informatik. https://doi.org/10.4230/OASIcs.ICCSW.2013.103

Shutenko, A., Shutenko, E., Sergeev, A., Ryzhkova, I., Talysheva, I., \& Tsareva, E. (2018). The use of modern ICT to provide students' self-realization in Russian higher school. Revista Espacios, 39(43). Retrieved from http://www.revistaespacios.com/a18v39n43/a18v39n43p15.pdf

Thomas, M. (2011). Digital education: Opportunities for social collaboration. New York, NY: Palgrave Macmillan. https://doi.org/10.1057/9780230118003

Weinberg, B. A., Hashimoto, M., \& Fleisher, B. M. (2009) Evaluating Teaching in Higher Education. The Journal of Economic Education, 40(3), 227-261. https://doi.org/10.3200/JECE.40.3.227-261

Yang, T.-C., Hwang, G.-J., \& Yang, S. J.-H. (2013). Development of an adaptive learning system with multiple perspectives based on students? Learning styles and cognitive styles. Educational Technology \& Society, 16(4), 185-200.

Yasir, E. A. M., \& Sami, M. S. (2011). An approach to adaptive E-learning hypermedia system based on learning styles (AEHS-LS): Implementation and evaluation. International Journal of Library and Information Science, $3(1), 15-28$. 